\title{
Editorial
}

\section{Vasculitis and granulomatosis of the respiratory tract}

In 1973 Liebow $^{1}$ grouped together a number of diseases under the heading of pulmonary angiitis and granulomatosis. These conditions, of which Wegener's granulomatosis is the most familiar, are characterised by chronic inflammation, granuloma formation, vasculitis, and necrosis. The lungs are primarily affected, but other organs may be involved. Because their clinical and radiological manifestations are similar, they are frequently confused, not only with each other but also with unrelated diseases. Furthermore, they are rare and experience in their diagnosis and management is limited: there has been little opportunity for the type of multidisciplinary approach which has, for instance, solved so many of the problems of glomerular disease.

Since Liebow's paper was published there have been significant advances in the treatment of these disorders, and new facts about their aetiology and their relationship to other diseases have emerged. The purpose of this editorial is to discuss the concept of pulmonary vasculitic and granulomatous disease in the light of more recent knowledge, to outline current trends in management, and to indicate the areas in which further investigation is needed.

\section{Classification}

The diseases at present classified as pulmonary vasculitis and granulomatosis are as follows: ${ }^{1-4}$ classical Wegener's granulomatosis; limited Wegener's granulomatosis; lymphomatoid granulomatosis; Churg-Strauss syndrome; necrotising sarcoid granulomatosis; bronchocentric granulomatosis.

The aetiology of most of these conditions is unknown or uncertain, and they must therefore be grouped according to their clinical and morphological features. The classification given here is convenient, and forms a useful basis for diagnosis. But it has no pathogenetic implications. The lung can only react to damage in a limited number of ways, and in fact each of these entities may have several different causes.

Address for reprint requests: Dr CW Edwards, Department of Histopathology, East Birmingham Hospital, Bordesley Green East, Birmingham.

\section{Definitions, clinical features, and pathology}

CLASSICAL WEGENER'S GRANULOMATOSIS

Since Wegener's granulomatosis was first described in the nineteen thirties, ${ }^{5-7}$ numerous papers dealing with its clinical features, pathology, and treatment have appeared. ${ }^{8-19} \mathrm{It}$ is characterised by a diagnostic triad consisting of granulomatous vasculitis of the upper and lower respiratory tract, a generalised small vessel vasculitis, and focal glomerulonephritis. ${ }^{9}$ The sexes are affected equally, with a peak incidence in the fifth decade. Untreated patients die in about five months, usually of renal failure.$^{8-10}$

The initial lesions almost always occur in the respiratory tract. ${ }^{16} 20$ Upper respiratory tract manifestations start as a persistent "cold", with rhinorrhoea, epistaxis, and sinusitis. ${ }^{19}$ Later there is obstruction and ulceration of the nose and nasopharynx, perforation of the nasal septum, saddle nose deformity, and eventually horrific destruction of mid-facial structures.

In $95 \%$ of patients the lungs are involved. 1620 Radiological changes are impressive, but signs and symptoms are often minimal. Main complaints are of chest pain, cough, and haemoptysis. Pneumothorax, hydropneumothorax, and bronchopleural fistula have been described, ${ }^{21} 22$ but clinical examination of the chest is usually unrewarding. Radiographs reveal a constantly changing pattern of opacities, predominantly in the lower lung fields. ${ }^{21-26}$ Cavitation is frequent. Occasionally there is a reticulonodular pattern, or pleural thickening and effusion, ${ }^{22}$ and endobronchial extension leads to segmental collapse in some cases. ${ }^{21} 26$ Hilar and mediastinal lymph node enlargement is rare. Respiratory function tests indicate obstructive and restrictive defects, and less commonly a reduction in diffusing capacity. ${ }^{27}$

Focal glomerulonephritis occurs in $85 \%$ of patients, ${ }^{20}$ often at a late stage. Hypertension is rare, ${ }^{8}$ and clinical manifestations of renal involvement are uncommon in the early stages, although some cases may present as Goodpasture's syndrome. ${ }^{28}$

Classical Wegener's granulomatosis is a multisystem disease, and structures other than the 
respiratory tract and kidneys are frequently involved. Patients often complain of systemic symptoms such as malaise, fever, and arthralgia. Ocular manifestations include proptosis, keratoconjunctivitis and granulomatous sclerouveitis; ${ }^{20}$ there may be a papular, vesicular or bullous rash, skin ulcers or lesions in old operation scars; 102930 lesions of the nervous system may produce a variety of neurological defects; 163132 and pericarditis and coronary arteritis occur in $15 \% .820$ Testicular, epididymal, and breast lesions have also been reported. 81032

Laboratory tests 161719 generally reveal a normochromic normocytic anaemia, a raised ESR, and a positive rheumatoid factor. Antinuclear factor and smooth muscle antibodies may be present. ${ }^{17}{ }^{33}$ IgA is generally raised, whereas IgG is normal: changes in IgM are inconstant. ${ }^{15-1733-35}$ IgE may be raised, and circulating antibodies have been demonstrated. ${ }^{33-35}$

On gross examination of the lungs there are one or more necrotic, sometimes cavitated masses, surrounded by a rim of pale, consolidated lung. ${ }^{8-13}$ The masses vary in size, and may sometimes involve an entire lobe. Histologically, in the lungs and other organs there is infiltration of the walls of veins and arteries by chronic inflammatory cells sometimes with granuloma formation. Vessels are often occluded by thrombus or granulation tissue, elastic fibres are destroyed, and there may be fibrinoid necrosis. Eosinophils are rare. Tissue adjacent to the affected vessels shows necrosis, chronic inflammation, and occasional granulomata.

The glomerulonephritis is focal and non-specific, but there is chronic inflammation and occasional granulomata in the interstitium, often with phlebitis and arteritis. ${ }^{14}{ }^{36}$ Immunofluorescent studies demonstrate IgG and complement, and at an ultrastructural level there are subepithelial and subendothelial electron dense deposits.

\section{LIMITED WEGENER'S GRANULOMATOSIS}

The concept of a variant of Wegener's granulomatosis with absent or minimal lesions outside the lungs, no glomerulonephritis, and an indolent course was proposed by Carrington and Liebow in $1966,{ }^{37}$ and reaffirmed by Liebow in $1973 .{ }^{1}$ Since 1966 further reports of this variant have appeared in the literature. ${ }^{38-42}$

Systemic and pulmonary symptoms and signs are similar to those of classical Wegener's granulomatosis, and the radiological and pathological changes in the lungs are identical. Painful subcutaneous nodules and involvement of the gastrointestinal tract or gall bladder may occur. ${ }^{37}$ Although focal glomerulonephritis by definition, is never present, granulomatous lesions are frequently found in the kidneys as well as in other organs. Differentiation of the two variants on histological grounds is impossible: the diagnosis can only be made by following the course of the disease.

LYMPHOMATOID GRANULOMATOSIS

Lymphomatoid granulomatosis is defined as an angiocentric and angiodestructive lymphoreticular and granulomatous disease affecting primarily the lungs. ${ }^{14344}$ Clinically and radiologically it is similar to Wegener's granulomatosis, but the cellular infiltrate is atypical, and a proportion of cases develop a lymphoma. Most patients are between 30 and 50 years of age, with a slight male preponderance. Onset is generally rapid, with cough, dyspnoea, haemoptysis, fever, malaise, and arthralgia. Skin manifestations, which may precede changes in the lungs, include an erythematous maculo-papular rash and subcutaneous, often ulcerating nodules. Involvement of the central or peripheral nervous system is common, and patients can present with a variety of neurological symptoms and signs. Radiographic abnormalities are similar to those of Wegener's granulomatosis. ${ }^{43} 4546$ Laboratory investigations reveal non-specific changes of no diagnostic value. Most patients die within two years of massive pulmonary or cerebral infiltration, but in some there is spontaneous remission or excellent response to treatment. 444

The naked eye appearance of the lungs is essentially the same as Wegener's granulomatosis, but the lesions tend to be more coalescent and destructive. Vascular and bronchial obstruction lead to infarction and obstructive pneumonitis: the development of these secondary phenomena and their subsequent partial resolution accounts for the constantly changing radiological picture. Lesions are found in the kidneys in about one-third of cases and in the brain in about one-quarter. ${ }^{43} 44$ Glomerulonephritis does not occur. The adrenals, heart, pancreas, or prostate may also be affected, but lymph nodes are not involved unless a lymphoma develops. Massive hepatic infiltration has been described, but is unusual. $\mathbf{4 3} 4448$

Histologically there is a proliferation of various chronic inflammatory cells intermingled with large atypical mononuclear elements. The proliferating cells have a propensity to invade arterial and venous vessels, which are occluded and eventually destroyed: fibrinoid necrosis is only seen in fulminating cases. ${ }^{49}$ The cellular infiltrate extends into bronchial walls and lung. Similar changes are seen in other organs, and in the skin there may be a lymphoma-like picture and widespread fat necrosis. ${ }^{435051}$ The lymphoma which sometimes develops is of an immunoblastic or plasmacytic and immunoblastic type. ${ }^{442}$ 


\section{CHURG-STRAUSS SYNDROME}

Churg-Strauss syndrome is a generalised necrotising vasculitis similar to polyarteritis nodosa. Unlike polyarteritis nodosa, however, there is lung involvement, a history of asthma, and a peripheral eosinophilia. It is more common in males and generally occurs in the fifth decade. ${ }^{54}$ Presenting features include bronchitis and asthma, transient or progressive pneumonic episodes, pleuritic pain and haemoptysis. There may be a petechial or purpuric rash, or nodular ulcerating masses in the subcutis. ${ }^{55}$ Signs and symptoms referable to the abdominal viscera and nervous system are similar to those of polyarteritis nodosa. Radiological findings in the chest vary between scattered areas of infiltration and massive diffuse or nodular lesions. ${ }^{54}$ Cavitation is rare. The chief laboratory abnormality is an eosinophilia which may rise to $81 \%$.

The basic histological change is a necrotising arteritis involving small veins and arteries down to a capillary level. 53545657 Vessel walls are infiltrated by neutrophil and eosinophil polymorphs, lymphocytes and plasma cells. Fibrinoid necrosis is common, and inflammatory cells extend into adjacent tissue. The lungs and bronchi are infiltrated by eosinophils. Necrotising granulomatous nodules are also a feature. These consist of a central area of altered collagen, surrounded by a palisade of radially arranged macrophages and giant cells. ${ }^{556}$

\section{NECROTISING SARCOID GRANULOMATOSIS}

This condition is a granulomatous disorder of the pulmonary vessels and parenchyma which appears to be intermediate between sarcoidosis and Wegener's granulomatosis. Since the original description by Liebow in $1973,{ }^{1}$ a total of 62 cases have been reported. ${ }^{58}$ It affects young or middle-aged adults, and is twice as common in females. Presenting features are non-specific and include malaise, fever, cough, and pleuritic pain. Some patients are asymptomatic. Physical examination is generally unrewarding, but radiologically there are usually one or more pulmonary opacities, or miliary mottling which may become nodular later. ${ }^{158} 59$ Cavitation does not occur, and hilar lymph node enlargement is uncommon. The characteristic lymphadenopathy, uveitis, and skin lesions of sarcoidosis are absent. Extrathoracic manifestations have only been recorded once, in a child with neurological and retinal involvement. ${ }^{60}$

The naked eye lesions consist of ill-defined areas of necrosis and consolidation in the lung. They are often more widespread than the radiographs suggest. ${ }^{59}$ Histologically the picture is one of epithelioid cell and giant cell granulomata with varying degrees of necrosis. Where the granulomata coalesce there is widespread colliquitive or coagulative necrosis with effacement of normal lung structures. ${ }^{15859}$ Pulmonary arteries and veins are infiltrated by necrotising granulomata or a more diffuse proliferation of giant cells and epithelioid cells. Near necrotic foci, vessel walls are destroyed by lymphocytes, plasma cells, and histiocytes. Bronchial involvement and obstruction with distal pneumonitis is common. Hilar nodes show either non-specific reactive change or occasional minute granulomata. The pleura may show fibrosis or granulomatous thickening.

\section{BRONCHOCENTRIC GRANULOMATOSIS}

Bronchocentric granulomatosis ${ }^{161}$ is, as the name implies, primarily a bronchial condition: vascular involvement is secondary. It is one of the disorders associated with hypersensitivity to Aspergillus, and is characterised by bronchiectasis, bronchial obstruction, and pulmonary fibrosis. Patients fall into two groups depending upon whether or not there is a history of asthma. ${ }^{61}$ The asthmatic group tends to be younger, with a mean age of 22 years: presenting symptoms are cough, chest pain, and dyspnoea, often associated with eosinophilia and a raised ESR. The mean age of the non-asthmatic group is around 50 years: symptoms in this group may be minimal, or again there may be cough, chest pain, or dyspnoea. Eosinophilia is less common.

In neither group can precipitin reactions to Aspergillus be relied upon for diagnosis, and fungi are rarely isolated from the sputum. Radiological changes tend to occur mainly in the upper lobes and may consist of rounded masses or areas of consolidation and atelectasis. In $75 \%$ of cases lesions are unilateral.

On gross examination bronchi are dilated, filled with yellow-white cheesy material, and surrounded by cuffs of grey-white tissue. At a microscopic level in early lesions part of the epithelial lining is replaced by spindle-shaped epithelioid cells arranged radially to the lumen. Later, when the epithelium is completely replaced, the lumen fills with necrotic cellular debris, producing the characteristic granulomatous appearance. In older lesions the central necrotic area becomes homogeneous, or it may contain masses of eosinophil granules. Tissue around the affected bronchi are infiltrated by chronic inflammatory cells, eosinophils being more prominent in the asthmatic group. Pulmonary arteries may be involved by direct extension, with intimal thickening on the side adjacent to the bronchus. The submucosa of large central bronchi is often infiltrated by chronic inflammatory cells: occasionally there are granulomata in 
the subepithelial layer, and there may be a striking chondritis and perichondritis. Fungal hyphae are frequently seen in the bronchial lumens in asthmatic patients.

\section{Diagnosis}

The most common diagnostic problem posed by this group of conditions is that of a patient with radiological opacities in the lungs. Clearly the differential diagnosis embraces almost any pulmonary disease, but there are a number of useful pointers. A history of asthma suggests Churg-Strauss syndrome or bronchocentric granulomatosis, and patients with classical Wegener's granulomatosis and ChurgStrauss syndrome ${ }^{62}$ often complain of upper respiratory tract symptoms. Physical examination is often unrewarding, but particular attention should be paid to the nose, nasopharynx and skin. The radiological lesions of Wegener's granulomatosis and lymphomatoid granulomatosis are often confined to the lower parts of the lung, and characteristically wax and wane..$^{132343}$ In Wegener's granulomatosis there is usually anaemia, a high ESR, a positive rheumatoid factor, and derangement of immune globulins. Churg-Strauss syndrome and bronchocentric granulomatosis are associated with an eosinophilia.

In patients with upper respiratory tract manifestations the differential diagnosis includes all the conditions which cause the "lethal midline granuloma" syndrome.6364 Again the history, clinical examination, and results of laboratory tests should suggest the nature of the underlying disorder.

The final diagnosis depends upon the correct interpretation of biopsy material. An adequate sample must be submitted to the pathologist. Biopsies of the bronchial mucosa, and transbronchial and needle biopsies of the lung parenchyma are too small and often unrepresentative: thoracotomy is essential. ${ }^{182565}$ Biopsies of the upper respiratory tract should be as large as possible. The focal glomerulonephritis of classical Wegener's granulomatosis is of a non-specific type; renal biopsy has a place in management, but will not in itself confirm the diagnosis.

\section{Treatment}

It is now generally accepted that the treatment of choice in classical Wegener's granulomatosis is cyclophosphamide, ${ }^{20} 6667$ which is curative in a large percentage of cases. It is often possible to taper off therapy when a complete remission has been obtained, although there may be problems with residual bronchial stenosis or interstitial lung disease. ${ }^{1827}$ Steroids have a place in the treatment of skin lesions, ocular manifestations and serosal involvement, ${ }^{18}$ and also in fulminating cases. ${ }^{20} 68$ Cyclophosphamide is advocated in the limited form of Wegener's granulomatosis by most authorities, but some suggest a period of observation when a solitary lesion has been excised.17

There is no established treatment for lymphomatoid granulomatosis. A variety of combinations of steroids and chemotherapy have been used, but none has been found particularly effective. ${ }^{17}{ }^{44}$ Fauci and his colleagues ${ }^{20}$ have found cyclophosphamide effective in the early stages of the disease, whereas others advocate excision and radiotherapy ${ }^{44}$ or radiotherapy alone. 6970 The situation regarding the treatment of the other members of this group of diseases is problematical. Steroids ${ }^{54}$ and cyclophosphamide 20 have both been used in the ChurgStrauss syndrome. Resection is curative in some cases of necrotising sarcoidal granulomatosis and bronchocentric granulomatosis, but steroids and chemotherapy still appear to have a place. ${ }^{5961}$

\section{Comment}

Classical Wegener's granulomatosis is a welldocumented clinico-pathological entity, and the site of the initial lesions, the immunoglobulin abnormalities, and the focal glomerulonephritis all suggest hypersensitivity to an inhaled antigen..$^{1316} 1734$ The nature of the offending antigen remains obscure. No micro-organisms have been implicated, although secondary infection with Staphylococcus aureus and Pseudomonas aerogenosa is common. ${ }^{16} 18$

The status of limited Wegener's granulomatosis is less certain at present. Many authorities feel that the two variants are part of the same disorder, and that the difference is only one of degree: the response to therapy is the same, and limited lesions may later become generalised. ${ }^{1516}$ The concept of an attenuated form of Wegener's granulomatosis is attractive, and it is tempting to place all slowly progressive and localised lesions with a similar histology into this category. But necrosis, angiitis, and granuloma ơ formation are seen in many disease processes. Ulbright and Katzenstein, ${ }^{71}$ in a review of solitary necrotising granulomas of the lung, found fungal or $\omega$ acid-fast organisms in $70 \%$. They emphasise that there is a spectrum of histological changes between $\stackrel{C}{C}$ Wegener's granulomatosis and infectious granu- $\mathbb{D}$ lomas, and advocate a thorough search for an infecting agent before a diagnosis is made.

An interesting re-classification of Wegener's $\stackrel{\vec{D}}{\vec{D}}$ granulomatosis and lymphomatoid granulomatosis was proposed by Saldana and his co-workers in $\stackrel{\complement}{\varrho}$ $1977 .{ }^{47}$ They arranged pulmonary angiitis and $\bar{Q}$ 
granulomatosis into three groups, and defined type I as lymphocyte depleted, type II as benign lymphocytic, and type III as malignant lymphoproliferative. All cases of classical Wegener's granulomatosis and some of the limited form were of type I. The cases of lymphomatoid granulomatosis all fell into the third group. Type II was a more indolent condition, often occurring in older patients and associated with a relatively good prognosis.

It is possible that lymphomatoid granulomatosis is the result of long continued antigenic stimulus in an abnormal host. Pre-existing chronic disease has been reported in a number of cases, 4344 immune impairment is sometimes a feature, ${ }^{52} \mathbf{7 2}$ and the disease has occurred in renal transplant recipients. ${ }^{49} 7374 \mathrm{Im}$ munological and ultrastructural studies indicate an abnormal proliferation of $\mathbf{B}$ cells, which may progress to a malignant lymphoma. ${ }^{52}$ Parallels may be drawn with Sjögren's syndrome and angioimmunoblastic lymphadenopathy, in which there is immune deficiency, lymphoid proliferation, and an increased incidence of lymphoma. ${ }^{4352}$

There is now some doubt concerning the position of lymphomatoid granulomatosis as a distinct entity. Malignant midline reticulosis, or polymorphic reticulosis, is one of the many disorders which cause the "lethal midline granuloma" syndrome.6364 Histologically it is identical to lymphomatoid granulomatosis, and it has been suggested that the two conditions are essentially the same. ${ }^{3} 7576$ The situation is further confused by reports of lymphomatoid granulomatosis affecting the upper respiratory tract and abdominal organs. ${ }^{73}$ 78-80

Churg-Strauss syndrome and polyarteritis nodosa are at the two ends of the systemic necrotising vasculitis spectrum. ${ }^{20}$ Polyarteritis nodosa affects only medium-sized systemic arteries: the pulmonary vasculature is not involved. A history of allergy and a peripheral eosinophilia are unusual. Nevertheless the two disorders are not completely clear cut, and some patients have a vasculitis with the characteristics of both-the so-called "overlap syndrome".20

The aetiology of necrotising sarcoidal granulomatosis is unknown, although in one case Aspergillus fumagatus was demonstrated by immunofluorescence. ${ }^{58}$ Some authorities regard it as a variant of sarcoidosis, ${ }^{59}$ whereas Saldana ${ }^{80}$ is of the opinion that it is a distinct pulmonary angiitis. Vascular involvement is common in typical pulmonary sarcoidosis, ${ }^{81}$ and nodular radiographic opacities may be seen. ${ }^{82} 83$ But on the other hand diffuse angiitis, necrosis, and absence of lesions in hilar lymph nodes and extrathoracic organs all suggest a separate disease.

Liebow included bronchocentric granulomatosis among the granulomatous and angiitic lung diseases, but it now seems likely that this is basically a necrotising bronchitis caused by hypersensitivity to fungi of the Aspergillus type: vascular involvement is secondary. ${ }^{61}$ Although correct in the context of the original paper, the inclusion of this entity with the pulmonary vasculitides now seems inappropriate.

To summarise then, the pulmonary angiitic and granulomatous diseases are a heterogeneous group in which the common theme is a disturbance of the immune system. We need to know much more about the precipitating factors and how they produce changes in the pulmonary vasculature and parenchyma. Bronchocentric granulomatosis should perhaps be placed in a separate category, the existence of a limited form of Wegener's granulomatosis as an entity is questionable, and the relationship of necrotising sarcoid granulomatosis to other conditions requires elucidation. Nevertheless, the present classification, although far from ideal, is a useful aide-memoire to diagnosis and management, which in the end is what clinical medicine and pathology is all about.

CW EDWARDS

Department of Histopathology, East Birmingham Hospital, Birmingham

\section{References}

${ }^{1}$ Liebow AA. Pulmonary angiitis and granulomatosis. Am Rev Respir Dis 1973;108:1-18.

${ }^{2}$ Lie JT. Nosology of pulmondary vasculitides. Mayo Clin Proc 1977;52:520-2.

${ }^{3}$ Leu HJ. Pathergic granulomatoses. Pathomorphology of classical and limited form of Wegener's granulomatosis, of lymphomatoid granulomatosis and of eosinophilic granulomatous angiitis. Vasa 1979;8:203-12.

4 Deremee RA, Weiland LH, McDonald TJ. Respiratory vasculitis. Mayo Clin Proc 1980;55:492-8.

${ }^{5}$ Klinger $H$. Grenzformen der Periarteriitis nodosa. Frankfurt $Z$ Pathol $1931 ; 42: 455-80$

- Wegener F. Über generalisierte, septische Gefässerkrankungen. Verh Dtsch Ges Pathol 1936;29:202-10.

7 Wegener F. Úber eine rhinogene Granulomatose mit besonderer Beteiligung des Arteriensystems. Beitr Pathol Anat 1939;102:36-8.

${ }^{8}$ Fahey JL, Leonard E, Churg J, Godman G. Wegener's granulomatosis. Am J Med 1954;17:168-79.

${ }^{9}$ Godman GC, Churg J. Wegener's granulomatosis. Pathology and review of the literature. AMA Arch Path 1954;58:533-53.

10 Walton EW. Giant cell granuloma of the respiratory tract (Wegener's granulomatosis). $\mathrm{Br} \mathrm{Med} J$ 1958;2:265-70.

${ }^{11}$ Israel HL, Patchefsky AS. Wegener's granulomatosis of lung: diagnosis and treatment. Experience with 12 cases. Ann Intern Med 1971;74:881-91.

12 Fauci AS, Wolff SM. Wegener's granulomatosis: studies in eighteen patients and a review of the literature. Medicine (Baltimore) 1973;52:535-61.

${ }^{13}$ Patchefsky AS, Israel HL. Pulmonary Wegener's granulomatosis. Ann Clin Lab Sci 1973;3:249-58.

${ }^{14}$ Wolff SM, Fauci AS, Horn RG, Dale DC. Wegener's 
granulomatosis. Ann Intern Med 1974;81:513-25.

15 Deremee RA, McDonald TJ, Harrison EG, Coles DT. Wegener's granulomatosis. Anatomic correlates, a proposed classification. Mayo Clin Proc 1976;51:777-81.

${ }^{16}$ Fauci AS, Wolff SM. Wegener's granulomatosis and related diseases. $D M$ 1977;23:3-36.

17 Israel HL, Patchefsky AS, Saldana MJ. Wegener's granulomatosis, lymphomatoid granulomatosis, and benign lymphocytic angiitis and granulomatosis of lung. Recognition and treatment. Ann Intern Med 1977;87: 691-9.

${ }^{18}$ Flye MW, Mundinger GH, Fauci AS. Diagnostic and therapeutic aspects of the surgical approach to Wegener's granulomatosis. J Thorac Cardiovasc Surg 1979;77:3317.

${ }^{19}$ McDonald TJ, Deremee RA, Weiland LH. Wegener's granulomatosis and polymorphic reticulosis-two diseases or one? Experience with 90 patients. Arch Otolaryngol $1981 ; 107: 141-4$.

20 Fauci AS, Haynes BF, Katz P. The spectrum of vasculitis: clinical, pathologic, immunologic, and therapeutic considerations. Ann Intern Med 1978;89:660-76.

${ }^{21}$ Maguire R, Fauci AS, Doppman JL, Wolff SM. Unusual radiographic features of Wegener's granulomatosis. AJR 1978;130:233-8.

${ }^{22}$ Epstein DM, Gefter WB, Miller WT, Gohel V, Bonavita JA. Spontaneous pneumothorax: an uncommon manifestation of Wegener's granulomatosis. Radiology 1980;135:327-8

${ }^{23}$ Gohel VK, Dalinka MK, Israel HL, Libschitz HI. The radiological manifestations of Wegener's granulomatosis. Br J Radiol 1973;46:427-32.

24 Gonzalez L, Van Ordstrand HS. Wegener's granulomatosis. Radiology 1973;107:295-300.

${ }^{25}$ Landman S, Burgener F. Pulmonary manifestations in Wegener's granulomatosis. Am J Roentgenol Radium Ther Nucl Med 1974;122:750-7.

${ }^{26}$ Farrelly C, Foster DR. Atypical presentation of Wegener's granulomatosis. Br J Radiol 1980;53:721-2.

27 Rosenberg DM, Weinberger SE, Fulmer JD, Flye MW, Fauci AS, Crystal RS. Functional correlates of lung involvement in Wegener's granulomatosis. Use of pulmonary function tests in staging and follow-up. $A m J$ Med 1980;69:387-94.

${ }^{28}$ Hensley MJ, Feldman NJ, Lazarus JM, Galvanek EG. Diffuse pulmonary haemorrhage and rapidly progressive renal failure. An uncommon presentation of Wegener's granulomatosis. Am J Med 1979;66:894-8.

${ }^{29}$ Reed WB, Jensen AK, Konwaler BE, Hunter D. The cutaneous manifestations in Wegener's granulomatosis. Acta Derm Venereol (Stockh) 1963;43:250-64.

30 Kraus Z, Vortel V, Fingerand A, Salavec M, Kotch V. Unusual cutaneous manifestations in Wegener's granulomatosis. Acta Derm Venereol (Stockh) 1965;45: 288-94.

31 Drachman DA. Neurological complications of Wegener's granulomatosis. Arch Neurol 1963;8:145-55.

32 Oimomi M, Suehiro I, Mizuno N, Baba S, Okada S Kanazawa Y. Wegener's granulomatosis with intracerebral granuloma and mammary manifestations. Report of a case. Arch Intern Med 1980;140:853-4.

${ }^{33}$ Shillitoe EJ, Lehner T, Lessof MH, Harrison DFN. Immunological features of Wegener's granulomatosis. Lancet $1974 ; 1: 281-4$

34 Conn DL, Gleich GJ, Deremee RA. Raised serum immunoglobulin E in Wegener's granulomatosis. Ann Rheum Dis $1976 ; 35: 377-80$.

${ }^{35}$ Howell SB, Epstein WV. Circulating immunoglobulin complexes in Wegener's granulomatosis. $\mathrm{Am} \mathrm{J} \mathrm{Med}$
1976;60:259-68.

${ }^{36}$ Horn RG, Fauci AS, Rosenthal AS, Wolff SM. Renal कै biopsy pathology in Wegener's granulomatosis. Am J Pathol 1974;74:423-33.

${ }^{37}$ Carrington CB, Liebow AA. Limited forms of angiitis and granulomatosis of Wegener's type. Am J Med 1966;41 : 497-527.

${ }^{38}$ Bernier J, Charbonneau R, Sestier F. A propos d'une forme localisée de granulomatose de Wegener. Union Med Can 1969;98:44-54.

${ }^{39}$ Asin HR, Wagenaar JPM, Swierenga J. The mitigated form of Wegener's disease. Scand J Respir Dis 1972;53: 367-74.

10 Davis RW, Fetter BF, Young WG. Wegener's granulomatosis. Two patients presenting with solitary pulmonary lesions and review of eleven other cases. Ann Thorac Surg 1972;13:427-34.

41 Donald KJ, Edwards RL, McEvoy JDS. An ultrastructural study of the pathogenesis of tissue injury in limited Wegener's granulomatosis. Pathology 1976;8:161-9.

${ }^{42}$ Hsu JT. Limited form of Wegener's granulomatosis. Chest 1976;70:384-5.

${ }^{43}$ Liebow AA, Carrington CRB, Friedman PJ. Lymphomatoid granulomatosis. Hum Pathol 1972;3:457-558.

${ }^{44}$ Katzenstein AL, Carrington CB, Liebow AA. Lymphomatoid granulomatosis. A clinicopathologic study of 152 cases. Cancer 1979;43:360-73.

45 Herman PG, Hillman B, Pinkus G, Harris GC. Unusual noninfectious granulomas of the lung. Radiology 1976; $121: 287-92$.

${ }^{46}$ Hicken P, Campbell Dobie J, Frew E. The radiology of lymphomatoid granulomatosis in the lung. Clin Radiol 1979;30:661-4

47 Saldana M, Patchefsky AS, Israel HI, Atkinson GW. Pulmonary angiitis and granulomatosis. The relationship between histological features, organ involvement and response to treatment. Hum Pathol 1977;8:391-409.

48 Schjølseth SA, Blom GP. Lymphomatoid granulomatosis of the lung, liver and spleen. Scand J Haematol 1978;21 : 104-8.

${ }^{49}$ Hammar SP, Gortner D, Sumida S, Bockus D. Lymphomatoid granulomatosis: association with retroperitoneal fibrosis and evidence of impaired cell mediated immunity. Am Rev Respir Dis 1977;115:1045-50.

${ }^{50}$ Kay S, Fu Y, Minars N, Brady JW. Lymphomatoid granulomatosis of the skin: light microscopic and ultrastructural studies. Cancer 1974;34:1675-82.

${ }^{51}$ Gross PR. Lymphomatoid granulomatosis. Cutis 1980;25: 305-9.

52 Bender BL, Jaffe R. Immunoglobulin production in lymphomatoid granulomatosis and relation to other "benign" lymphoproliferative disorders. Am J Clin Pathol 1980;73:41-7.

${ }^{53}$ Churg J, Strauss L. Allergic granulomatosis, allergic angiitis and periarteritis nodosa. Am J Pathol 1951;27: 277-301.

${ }^{54}$ Chumbley LC, Harrison EG, Deremee AA. Allergic granulomatosis and angiitis (Churg-Strauss syndrome). Mayo Clin Proc 1977;52:477-84.

${ }_{55}$ Dicken $\mathrm{CH}$, Winkelmann RK. The Churg-Strauss granuloma: cutaneous, necrotising, palisading granuloma in vasculitis syndromes. Arch Pathol Lab Med 1978;102: 576-80.

${ }_{56}$ Veevaete F, Van Der Straeten M, De Vos M, Roels H. Allergic granulomatous angiitis. Scand $J$ Respir Dis $1978 ; 59: 287-96$.

57 Clausen KP, Bronstein H. Granulomatous pulmonary arteritis. A hypereosinophilic syndrome. Am J Clin Pathol 1974;62:82-7. 
58 Corrin B, Spencer H. Some aspects of pulmonary pathology. In: Anthony PP, MacSween RNM, eds. Recent advances in histopathology no 11. Edinburgh: Churchill Livingstone, 1981.

${ }^{59}$ Churg A, Carrington CB, Gupta R. Necrotising sarcoid granulomatosis. Chest 1979;76:406-13.

${ }^{60}$ Beach R, Corrin B, Scopes JW, Graham E. Necrotising sarcoid granulomatosis with neurological lesions in a child. J Pediatr 1980;97:950-3.

${ }^{61}$ Katzenstein AL, Liebow AA, Friedman PJ. Bronchocentric granulomatosis, mucoid impaction and hypersensitivity reactions to fungi. Am Rev Respir Dis 1975; $111: 497-537$.

${ }^{62}$ Olsen KD, Neel HB, Deremee RA, Weiland LH. Nasal manifestations of allergic granulomatosis and angiitis (Churg-Strauss syndrome). Otolaryngol Head Neck Surg 1980;88:85-9.

${ }^{63}$ McGuirt WF, Rose EF. Lethal midline granuloma: a pathological spectrum. J Laryngol Otol 1976;90:459-66.

${ }^{64}$ Wetmore SJ, Platz CE. Idiopathic midface lesions. Ann Otol Rhinol Laryngol 1978;87:60-9.

${ }^{65}$ Allen AR, Moen CW. Wegener's granulomatosis. $J$ Thorac Cardiovasc Surg 1965;49:388-97.

${ }^{66}$ Novack SN, Pearson CM. Cyclophosphamide therapy in Wegener's granulomatosis. N Engl J Med 1971;284: 938-42.

${ }^{67}$ Reza MJ, Dornfeld L, Goldberg LS, Bluestone R, Pearson CM. Wegener's granulomatosis. Long term follow-up of patients treated with cyclophosphamide. Arthritis Rheum 1975;18:501-6.

${ }^{68}$ Harrison HL, Linshaw MA, Lindsley CB, Cuppage FE. Bolus corticosteroids and cyclophosphamide for initial treatment of Wegener's granulomatosis. JAMA 1980; 244:1599-600.

${ }^{69}$ Fuller P, Hafermann D, Byrd R, Jenkins D. Use of irradiation in lymphomatoid granulomatosis. Chest $1978 ; 74: 105-6$.

${ }^{70}$ Shank BB, Kelley CD, Nisce LZ, Nori D. Radiation therapy in lymphomatoid granulomatosis. Cancer 1978; 42:2572-80.
7 Ulbright TM, Katzenstein AL. Solitary necrotizing granulomas of the lung. Differentiating features and etiology. Am J Surg Pathol 1980;4:13-28.

${ }^{72}$ Cohen ML, Dawkins RL, Henderson DW, Sterrett GF, Papadimitrou JM. Pulmonary lymphomatoid granulomatosis with immunodeficiency terminating as malignant lymphoma. Pathology 1979;11:537-50.

${ }^{73}$ Gardiner GW. Lymphomatoid granulomatosis of the larynx in a renal transplant recipient. $J$ Otolaryngol 1979;8:549-55.

74 Walter M, Thomson NM, Dowling J, Fox R, Atkins RC. Lymphomatoid granulomatosis in a renal transplant recipient. Aust NZ J Med 1979;9:434-6.

${ }^{75}$ Deremee RA, Weiland LH, McDonald TJ. Polymorphic reticulosis, lymphomatoid granulomatosis. Two diseases or one? Mayo Clin Proc 1978;53:634-40.

${ }^{76}$ Crissman JD. Midline malignant reticulosis and lymphomatoid granulomatosis. A case report. Arch Pathol Lab Med 1979;103:561-4.

${ }^{77}$ Chen KTK. Abdominal form of lymphomatoid granulomatosis. Hum Pathol 1977;8:99-103.

${ }^{78}$ Singh G, Hellstrom HR. Lymphomatoid granulomatosis: report of a case without pulmonary lesions and with ischaemic colitis, probably a sequel to granulomatosis. Hum Pathol 1978;9:364-6.

79 Gupta S, Gupta OP. Lymphomatoid granulomatosis of the oropharynx. Ear Nose Throat J 1980;59:152-4.

80 Saldana MJ. Necrotizing sarcoid granulomatosis: clinicopathologic investigations in 24 patients (abstract). Lab Invest $1978 ; 38: 364$.

${ }^{81}$ Rosen Y, Moon S, Huang CT, Gourn A, Lyons HA. Granulomatous pulmonary angiitis in sarcoidosis. $A m \mathbf{J}$ Clin Pathol 1977;67:213.

${ }^{82}$ Sharma OP, Hewlett R, Gordonson J. Nodular sarcoidosis: an unusual radiographic appearance. Chest $1973 ; 64$ 189-92.

${ }^{83}$ Onal E, Lopata M, Lourenco RV. Nodular pulmonary sarcoidosis. Clinical roentgenographic and physiologic course in five patients. Chest 1977;72:296-300. 